\title{
Effects on Proposed End-milling Condition Decision-Support System Using Data Mining on Saving Power Consumption
}

\author{
Hiroyuki KODAMA ${ }^{1}$, Toshiki HIROGAKI ${ }^{2}$, Eiichi AOYAMA ${ }^{2}$, Keiji OGAWA ${ }^{3}$ and Junichi SAKAMOTO ${ }^{1}$ \\ ${ }^{1}$ Department of Mechanical Engineering, Doshisha University Graduate School, Japan, etl1302@mail4.doshisha.ac.jp \\ 2 Department of Mechanical Engineering, Doshisha University, Japan, thirogak@mail.doshisha.ac.jp, \\ eaoyama@mail.doshisha.ac.jp \\ ${ }^{3}$ Department of Mechanical Systems Engineering, University of Shiga Prefecture, Japan, ogawa@mech.usp.ac.jp
}

\begin{abstract}
:
Choosing cutting tools and conditions depends on expert engineers' knowledge and experience, and often a lengthy process of trial and error is required before they obtain appropriate end-milling conditions. We have previously proposed data mining methods to make decisions about end-milling conditions on the basis of catalog data. We cut hardened die steel JIS SKD61 under three kinds of end-milling conditions: catalog conditions, mined conditions, expert engineer conditions. We used LCA to quantitatively evaluate the environmental impact resulting from these conditions. Results showed that the mined condition is environmentally superior to the catalog conditions.
\end{abstract}

\section{Keywords: Data mining, End-milling, Manufacturing system, Environmental Impact, LCA, Learning} curve

\section{Introduction}

Currently, metal molds are designed by CAD, CL data are being made from CAM, and metal molds are being manufactured at machining centers. The CAM system can only calculate the tool path that followed to the metal mold shape designed using CAD system. However, the tools and end-milling conditions (cutting speed $V \mathrm{~m} / \mathrm{min}$, feed rate $f \mathrm{~mm} /$ tooth, axial depth of cut $\mathrm{Ad} \mathrm{mm}$, radius depth of cut $R d \mathrm{~mm}$ ) chosen depend on the expert engineers' knowledge and experience. Most engineers undergo a process of trial and error until they obtain appropriate end-milling conditions, which leads to wasted materials as well as increased costs and a longer developing time.

In the $21^{\text {st }}$ century, eco-friendly products and manufacturing practices are becoming more mainstream, and much work has been done in the manufacturing field to achieve minimal $\mathrm{CO}_{2}$ emission, which is a requirement of ISO14001. A great deal of research has been conducted in the area of machining most related to process-level and system-level activities and improvements. For example, various studies have focused on MQL machining and the cold-jet machining method and have evaluated the environmental impact during the processing step [1-5]. System-level environmental analysis of machining, including milling, turning, and drilling, has been proposed [6-7]. Other studies have focused on evaluations to predict the environmental impact which various systems have on machining [8-9]. This environmental impact prediction system has already been applied to the production process. However, there has been little research on reducing abolishment and the length of the mold

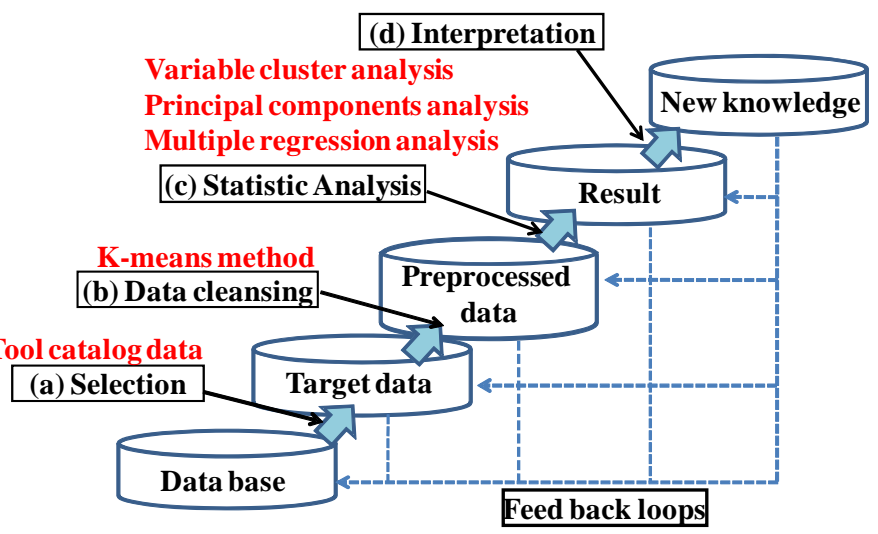

Figure 1: Catalog mining process.

manufacturing trial stage from the viewpoint of environmental impact.

We have previously proposed data mining methods to make decisions about end-milling conditions on the basis of catalog data, and we have clarified the combination effect of hierarchical and non-hierarchical clustering [10-11]. Even unskilled engineers can use our “end-milling conditions decision-support system" to instantly determine stable end-milling conditions. In this study, we investigated different end-milling conditions in terms of power consumption to evaluate the effectiveness of our system. The environmental impact under various end-milling conditions was quantitatively evaluated using life cycle assessment (LCA). We cut hardened die steel JIS SKD61 (hereafter referred to as SKD61), under three different end-milling conditions: those recommended in the catalog, those derived by data mining, and proven end-milling conditions recommended by veteran engineers for die machining (rough processing). 


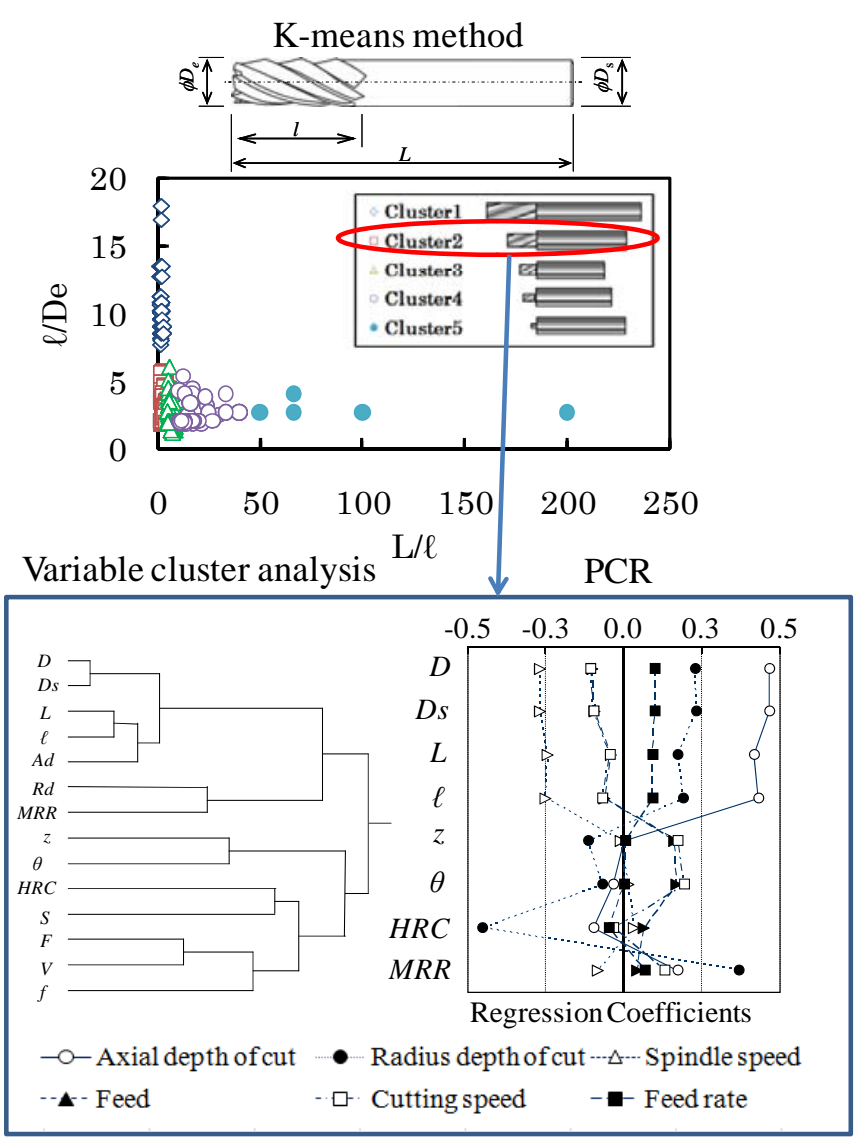

Figure 2: Data mining results of Cluster 2.

\section{Data mining}

\subsection{Catalog mining process}

In this study, we dealt with catalog mining, which is a data mining method that can be used to extract knowledge hidden in catalog data [10-11]. The flow of the catalog mining process we used is shown in Fig. 1. Data on the square end-mills listed in the catalog from the largest tool maker in Japan (company A) were selected and stored as target data. The end-milling conditions recommended by the cutting tool maker constitute a massive amount of accurate data reflecting solid experimental results which the tool maker has personally overseen. In the data cleansing process, the target data was grouped using the K-means method, which is a non-hierarchical clustering method for the tool shape. It was performed using VMStudio (Mathematical Systems, Inc.). In the next step, as a statistical analysis, we determined a tree data structure using variable cluster analysis, which is a hierarchical clustering method. We used multiple regression analysis to predict the conditional equations. Because catalog mining is simple, fast, and comparatively more intelligible than other data mining methods, it should be easy for analysts who may be unfamiliar with data mining techniques to use.

\subsection{Catalog mining results}

Figure 2 shows a diagram of a cutting tool and the results obtained by the K-means method. It also shows the results of variable cluster analysis and PCR on Cluster 2 (typical shape). We used three variables $(L / \ell$, $\ell / D e$, and $D s / D e$ ) and visualized the shape of the end-mill with the K-means method. Cluster 2 accounts for $56 \%$ of the total data, which is the highest amount. We used variable cluster analysis and principal component regression (PCR) for each cluster classified by the K-means method from the viewpoint of end-mill shape. This type of analysis shows the relationships between the structure of the predictor variables and any correlation with the criterion variables that were quantitatively calculated by PCR. Using the results of the variable cluster analysis and the PCR, we compared the correlation coefficients with the criterion variable between high predictor variables and reduced low correlation. We were able to determine the end-milling condition decision equations using the variables that were determined to be significant in the multiple regression analysis. As an example, the equations for Cluster 2 consisted of a criterion variables vector, a coefficient matrix, and a predictor variables vector as shown in Eq. (1). We consider the determination coefficient $R$ to be generally significant in cases where it is 0.5 or more.

$\left[\begin{array}{c}A d(R 0.79) \\ R d(R 0.30) \\ S(R 0.26) \\ F(R 0.04) \\ V(R 0.04) \\ f(R 0.06)\end{array}\right]=\left[\begin{array}{ccccccc}0.87 & -0.13 & 0.12 & 0 & 0 & 0 & 2.50 \\ 0.07 & -0.04 & 0 & 0 & 0 & 0 & 2.39 \\ -222 & 53 & 0 & -132 & 0 & 0 & 7978 \\ -22 & 22 & 0 & 0 & -9 & 0 & 581 \\ 0 & 0.45 & 0 & 0 & 0.58 & -0.81 & 74 \\ 0.002 & 0 & 0 & 0 & 0 & 0 & 0.039\end{array}\right]\left[\begin{array}{c}D \\ H R C \\ L \\ l \\ \theta \\ z \\ 1\end{array}\right](1)$

\subsection{End-milling conditions and experimental set-up}

We performed cutting experiments and measured the consumed power of a machine tool under three end-milling conditions: those recommended by the catalog of company A, those derived by catalog mining, and proven end-milling conditions suggested by expert engineers. We cut SKD61, which is commonly used in die machining as a workpiece. Table 1 lists the data mining results obtained by substituting the tool parameters into the above equations (mined conditions), end-milling conditions recommended by the tool catalog (catalog conditions), and the end-milling conditions suggested by expert engineers (expert engineer). End-milling conditions suggested by expert engineers were obtained by several cutting experiments considering well-balanced both tool life and cutting efficiency. The slotting conditions of the catalog and the expert engineers were as follows: the axial depth of the cut $\mathrm{Ad}$ was 0.3 $\mathrm{mm}$, and the other end-milling conditions were the same as in side milling. We used tools ( $\varphi 6$ radius end-mill, company A), as shown in Fig. 3. The shape of the workpiece after cutting is shown in Fig. 4. The tool we used belongs to Cluster 2, which is the cluster with the most data. The experiments involved processing 
Table 1: Cutting conditions used in the experiments.

\begin{tabular}{c|c|c|c|c}
\hline Data type & Catalog conditions & Expert engineer & $\begin{array}{c}\text { Mined conditions } \\
\text { (Side milling) }\end{array}$ & $\begin{array}{c}\text { Mined conditions } \\
\text { (Slotting) }\end{array}$ \\
\hline Spindel speed rpm & 20000 & 9600 & 7739 & 4510 \\
\hline Feed mm/min & 7200 & 2304 & 2368 & 1082 \\
\hline Cutting speed m/min & 377 & 181 & 146 & 85 \\
\hline Feed rate mm/tooth & 0.06 & 0.04 & 0.05 & 0.04 \\
\hline Axial depth of cut mm & 6 & 4 & 9 & 2 \\
\hline Radius depth of cut mm & 0.30 & 0.30 & 0.50 & 6.00 \\
\hline MRR cc/min & 12.96 & 2.77 & 10.46 & 12.98 \\
\hline
\end{tabular}
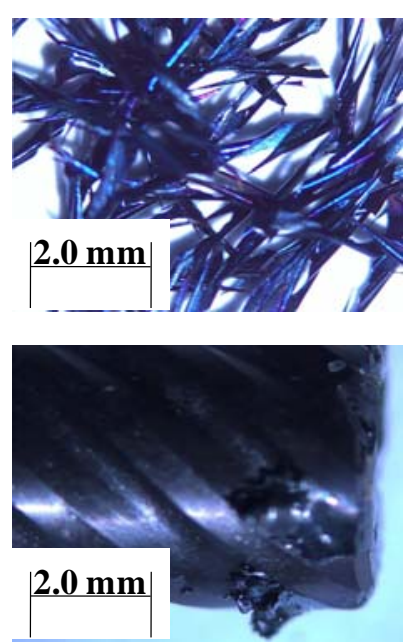

(a) Catalog conditions
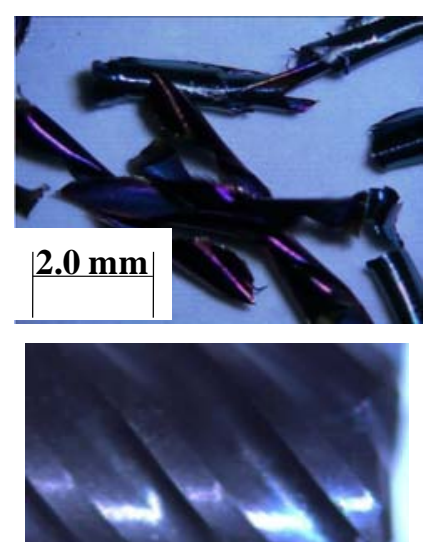

$2.0 \mathrm{~mm}$

(b) Mined conditions
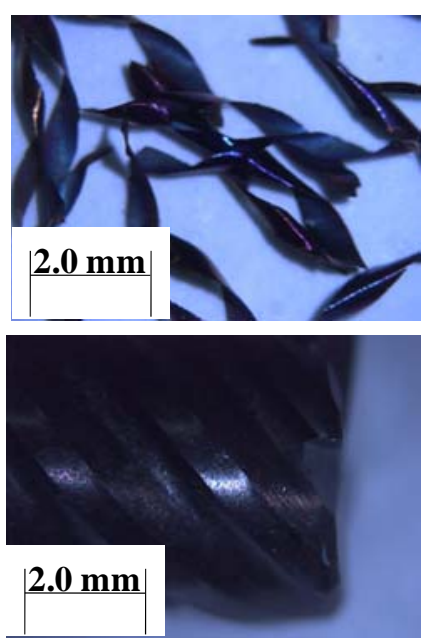

(c) Expert engineer

Figure 5: Appearance of chip and cutting edge.

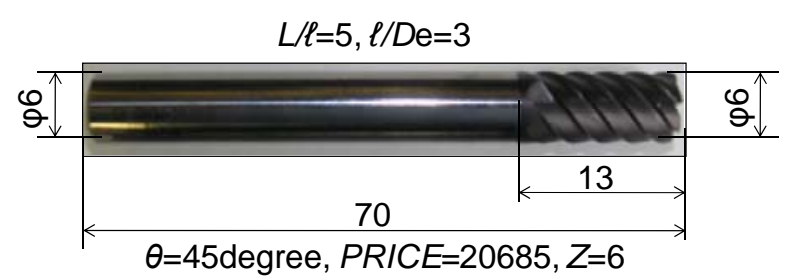

Figure 3: Tool shape parameters.
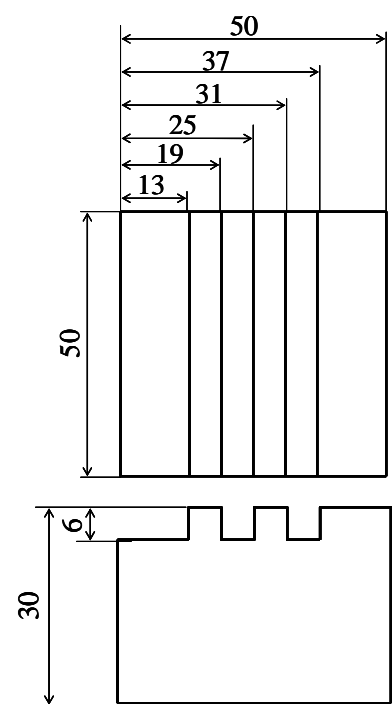

Figure 4: Workpiece procession. (down-cut, one pass) a flat surface. The machine tool was an ACCUMILL4000 made by Mori Seiki (maximum spindle speed: $20000 \mathrm{rpm}$ ). We performed precision cutting in which the tool runout had to be $5 \mu \mathrm{m}$ or less. The tool extension is $30 \mathrm{~mm}$. All the cuttings were conducted under dry conditions.

\subsection{Experimental results}

Figure 5 shows the cutting edge and the chips of the tools after the experiment. Under the catalog condition, chatter vibration occurred shortly after cutting the workpiece. While conducting slotting under the catalog condition, we had hardly started cutting before the tools began chattering and sparking. This meant we could not measure power consumption during slotting. The mined condition also had sparking, but despite this, we could cut to the end. The tools operated under the expert engineer condition showed very little galling, and the outside curl of the chips remained blue.

\section{Environmental impact assessment}

\subsection{Life cycle assessment}

Life cycle assessment (LCA), a method that quantitatively evaluates environmental impact in the life cycle of the excavation of material used for a product, from fabrication through to transfer, usage, and disposal, 
Table 2: Global warming characterization factors.

\begin{tabular}{c|c|c|c}
\hline & $\mathrm{CO}_{2}$ & $\mathrm{CH}_{4}$ & $\mathrm{~N}_{2} \mathrm{O}$ \\
\hline Global warming potential (GWP) & 1 & 21 & 310 \\
\hline
\end{tabular}

Table 3: Results of lifetime experiments.

\begin{tabular}{c|c|c|c}
\hline & Catalog conditions & Mined conditions & Expert engineer \\
\hline Longevity distance m & 43 & 50 & 501 \\
\hline Cutting distance mm & 2150 & 1250 & 2150 \\
\hline
\end{tabular}

\begin{tabular}{|c|c|c|}
\hline Setting objective & Inventory analysis & Impact evaluation \\
\hline \multirow{6}{*}{$\begin{array}{c}\text { Research object } \\
\text { Cutting tool } \\
\text { consumption } \\
\text { Power consumption } \\
\text { during cutting }\end{array}$} & Mine resource & Classification \\
\hline & & $\mathrm{CO}_{2}, \mathrm{CH}_{4}, \quad \mathrm{NO}_{2}$ \\
\hline & Production & $\frac{1}{\text { Charastorization }}$ \\
\hline & Use & Clobol uramina \\
\hline & Canon & \\
\hline & scrap & Integration \\
\hline
\end{tabular}

Figure 6: LCA flow.

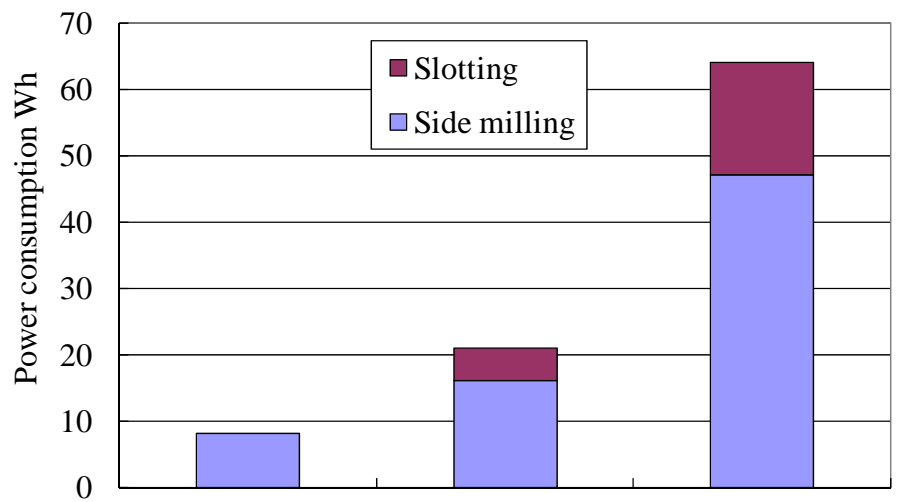

Catalog conditions Mined conditions Expert engineer

Figure 7: Power consumption under each cutting condition.

is the standard for measuring the contribution level of sustained economic development. As prescribed in ISO14042, LCA consists of four elements: goal and scope, life cycle inventory, life cycle impact assessment, and interpretation. We made a function of the object product and the standard to clearly perform LCA and set the goal and scope. Next, we determine the range of the process related to the life cycle of products and investigated the environmental impact. JEMAI-Pro was used as the LCA software. Background data was obtained from JEMAI-Pro archives.

\subsection{Research objective setup}

In this study, our aim was to evaluate the environmental impact under mined conditions derived from our previously proposed end-milling condition decision-support system by cutting SKD61 and comparing the catalog condition and expert engineer condition during side milling. The LCA flow is shown in
Fig. 6. Because environmental evaluation based on global warming in Japan, we selected global warming as the environmental effect item. We measured the amount of $\mathrm{CO}_{2}, \mathrm{CH}_{4}$, and $\mathrm{N}_{2} \mathrm{O}$ that were emitted, as these three are key factors influencing global warming. All emissions were converted to equivalent $\mathrm{CO}_{2}$ emissions by multiplying them by characterization factors. Their environmental impact as an indicator was calculated by adding all emissions. As shown in Table 2, the global warming potential (GWP) of 100-year impact was used as the characterization factor. In this study, the system boundary was limited to just one machine tool (ACCUMILL 4000) for the usage stage and cutting tool abolishment. This enables us to write off the materials and energy consumption used in machine tool construction and disposal. Work materials were also written off, because chips and broken cutting tools are not recycled for work and the tool used in precision cutting, and we did not consider chip recycling.

\subsection{Environmental impact of cutting tool}

We determined the environmental impact of producing and disposing of the cutting tool. This impact is expressed as

$$
T=\frac{T U T}{T L} \times(T P e+T D e) \times T W \times W
$$

$T$ : environmental impact of cutting tool $\mathrm{kg}-\mathrm{CO}_{2}$

$T L$ : tool life $\mathrm{m}$

TUT: cutting distance of a workpiece $\mathrm{m}$

TPe: environmental impact of cutting tool production $\mathrm{kg}-\mathrm{CO}_{2} / \mathrm{kg}$

TDe: environmental impact of cutting tool disposal 


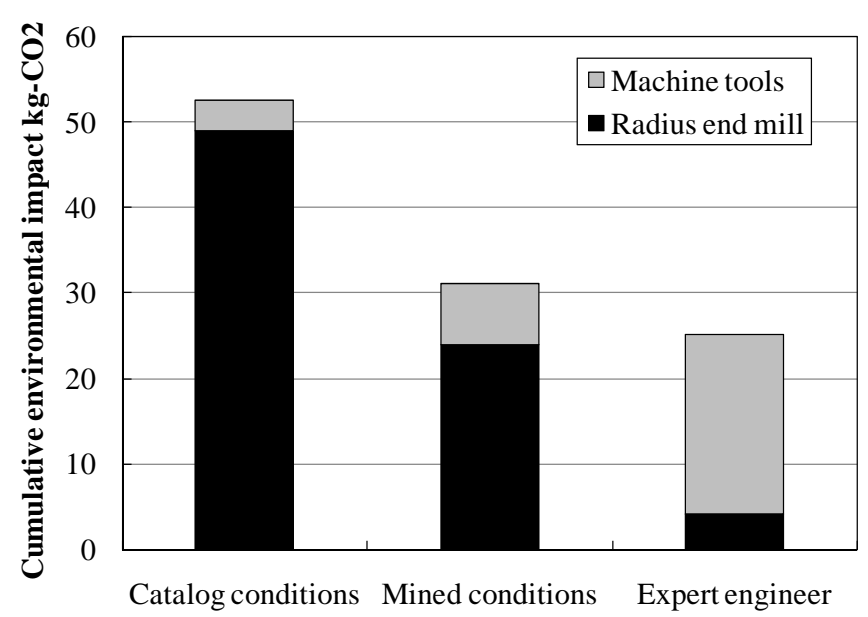

Figure 8: Cumulative environmental impact under each cutting condition.

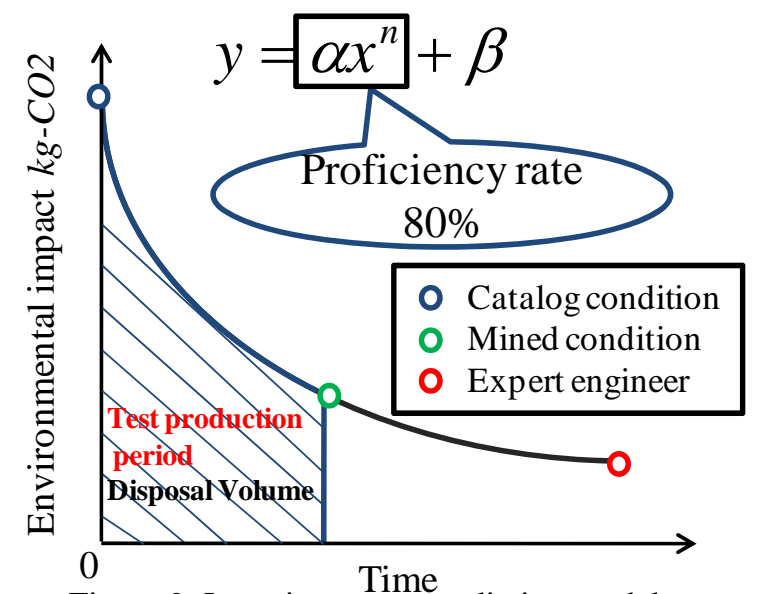

Figure 9: Learning curve prediction model.

$\mathrm{kg}-\mathrm{CO}_{2} / \mathrm{kg}$

$T W$ : tool weight kg

$W$ : number of workpieces

We used the $\mathrm{CO}_{2}$ discharge rates of cutting tool production and disposal proposed in a previous study [8]. These $\mathrm{CO}_{2}$ discharge rates refer to the environmental impact of cutting tool production $T P e=33.7 \mathrm{~kg}-\mathrm{CO}_{2} / \mathrm{kg}$ and the environmental impact of cutting tool disposal $T D e=1.3 \times 10^{-2} \mathrm{~kg}-\mathrm{CO}_{2} / \mathrm{kg}$. We consider the weight of the cutting tool used in this study (see Fig. 6) to be TW = $29 \mathrm{~g}$, which is given in Eq. (3) from Eq. (2).

$$
T=0.98 \times \frac{T U T \times W}{T L}
$$

The tool life experiment, which was done under three end-milling conditions is performed to use Eq. (3), was performed during the side milling in the down cut, one path direction. The experimental results as well as the cutting distance leading up to the finished shape (Fig. 4) under each end-milling conditions are shown in Table 3. This enabled us to calculate the environmental impact of the cutting tool during side milling under all three conditions. The environmental impact under the catalog condition during side milling $T_{c} \mathrm{~kg}-\mathrm{CO}_{2}$, under the mined condition during side milling $T_{m} \mathrm{~kg}-\mathrm{CO}_{2}$ and under the expert condition during side milling $T_{e}$ kg- $\mathrm{CO}_{2}$ are given as Eqs. (4), (5), and (6), respectively.

$$
\begin{aligned}
& T_{c}=4.9 \times 10^{-2} \times W \\
& T_{m}=2.4 \times 10^{-2} \times W \\
& T_{e}=4.2 \times 10^{-2} \times W
\end{aligned}
$$

\subsection{Environmental impact of machine tool's power consumption}

In this study, we set power consumption of machine tool (ACCUMILL4000) cutting one workpiece using the cemented carbide radius end-mill (as shown in Fig. 3) to inventory data as environmental impact of machine tool's power consumption. The measurement result is shown in Fig. 7. The power consumptions under the catalog, mined and expert engineer conditions during results, which demonstrate that high-speed cutting is predictably effective, have also been shown in other papers [7-8]. However, our study is slightly different in that we highlight the importance of appropriate end-milling conditions to enable long life cutting, especially when working with SKD 61 [12]. The environmental impact of the power consumption of the machine tool under catalog condition $E_{c} \mathrm{~kg}-\mathrm{CO}_{2}$, mined condition $E_{m} \mathrm{~kg}-\mathrm{CO}_{2}$, and expert engineer condition $E_{e}$ $\mathrm{kg}-\mathrm{CO}_{2}$ is shown below in Eqs. (7), (8), and (9), respectively.

$$
\begin{aligned}
& E_{c}=3.6 \times 10^{-3} \times W \\
& E_{m}=7.2 \times 10^{-3} \times W \\
& E_{e}=2.1 \times 10^{-2} \times W
\end{aligned}
$$

\subsection{Consideration}

We combined the cumulative environmental impact under the three end-milling conditions from the view point of global warming (from Eq. (4) to Eq. (9)) with the environmental impact of both the cutting tool and the power consumption. The cumulative environmental impact under catalog condition $C_{c} \mathrm{~kg}-\mathrm{CO}_{2}$, mined condition $C_{m} \mathrm{~kg}-\mathrm{CO}_{2}$, and expert engineer condition $C_{e}$ $\mathrm{kg}-\mathrm{CO}_{2}$ are given in Eqs. (10), (11), and (12), respectively.

$$
\begin{aligned}
& C_{c}=5.2 \times 10^{-2} \times W \\
& C_{m}=3.1 \times 10^{-2} \times W \\
& C_{e}=2.5 \times 10^{-2} \times W
\end{aligned}
$$

Firstly, we compared with cumulative environmental impact in three end-milling conditions from Eqs. (10) (12). $C_{m}$ roughly accounts for $60 \%$ of the $C_{c}, C_{m}$ roughly accounts for $124 \%$ of the $C_{e}$. Second, we calculated the ratio between the environmental impact of the tool and its power consumption to obtain the overall cumulative 
environmental impact from Eqs. (3) - (6). As an example, the cumulative environmental impact under all conditions is shown Fig. 8, when 1000 workpieces (as shown in Fig. 4) were produced. The environmental impact of the cutting tool accounted for $17 \%$ of the cumulative environmental impact under the expert conditions, $77 \%$ under the mined condition, and 94\% under the catalog condition. This demonstrates that the expert condition is preferable for reducing tool consumption and the catalog condition is preferable for reducing machine tool power consumption. In the case of the expert condition, the end-milling condition that reduces tool consumption has a smaller cumulative environmental impact than the end-milling condition that reduces machine tool power consumption during cutting. The tool consumption was the lowest under the expert condition, which indicates that this condition has the most usefulness from a global warming perspective. However to reach the expert condition, it is necessary to repeat several trial-and-error processes, which consumed not only time but also cutting tools and electric power. Therefore, because the mined conditions show the next best usefulness, we designed an index model of the environmental impact in the technical mastering process under this condition, the model of which is shown in Fig. 9. This figure shows the environmental impact prediction model, which we consider based on the learning curve [13]. $\beta$ refers to machine tool usage. The area indicated by the diagonal lines shows the cumulative environmental impact during the period between the catalog and mined conditions. The results show that unskilled engineers could decrease the cumulative environmental impact by working under the mined condition in the initial stage. Recommending the use of the mined condition in the initial stage is therefore considered best.

\section{Conclusion}

High-speed cutting under a catalog condition can reduce a machine tool's electricity consumption, while reducing the consumption of a number of cutting tool used suppresses the cumulative environmental impact suppressive. For die steel SKD61 cutting, the mined conditions is more eco-friendly than the catalogrecommended condition. The use of our proposed learning curve model should result in shorter trial production times under mined conditions

\section{References}

[1] S. Touma et. Al., 2003, Evaluation of environmental burden in eco-friendly machining method using life cycle assessment method -Estimation of carbon dioxide emission in eco-friendly turning method-, Journal of the Japan Society for Precision Engineering, Vol. 69, No. 6, pp. 825-830. (in Japanese).
[2] M. Yokogawa et. Al., 2001, Evaluation of LCA and cost performance in eco-friendly turning method, The Japan Society of Mechanical Engineering, pp. 51-52. (in Japanese).

[3] H. Yoshimura, 2004, Study on eco-friendly oil on water drop cutting fluid, Journal of the Japan Society for Abrasive Technology, Vol. 48, No. 9, pp. 18-21. (in Japanese).

[4] Sreejith, P.S. and B.K.A. Ngoi, 2000, Dry machining of the future, Journal of Materials Processing Technology, Vol. 101, pp. 287-291.

[5] Sutherland, J.W., V.N. Kulur, and N.C. King, 2000, An experimental investigation of air quality in wet and dry turning, Annals of the CIRP, Vol. 49, pp. 61-64.

[6] Timothy Gutowski, Jeffrey Dahmus, and Alex Thiriez, 2006, Electrical energy requirements for manufacturing processes, Annals of the CIRP, pp. 1-5.

[7] Jeffrey B. Dahmus and Timothy G. gutowski, 2000, Recycle of Ceria-based Glass Polishing Powder Using $\mathrm{NaOH}$ Solution, The Chemical Society of Japan, No. 10, pp. 725-731.

[8] H. Narita et. Al., 2005, Development of prediction system of environmental burden for machine tool operation (1st report, proposal of calculation method of environmental burden), Transaction of the Japan Society of Mechanical Engineers, Series C, Vol. 71 No. 704, pp. 280-287. (in Japanese).

[9] H. Narita et. Al., 2005, Development of prediction system of environmental burden for machine tool operation (2nd report, proposal of evaluation indicator for eco-friendly), Transaction of the Japan Society of Mechanical Engineers, Series C, Vol. 72 No. 715, pp. 241-246. (in Japanese).

[10] T. Hirogaki et. Al., 2011, Decision methodology of end-milling conditions using data-mining, Journal of the International Societies for Precision Engineering and Nanotechnology, Vol. 35, pp. 197-203.

[11] H. Kodama et. Al., 2011, Determination of end-milling conditions using data-mining -Combination effects of hierarchical and nonhierarchical clustering for tool catalog-data-, Journal of the Japan Society for Abrasive Technology, Vol. 55, No. 1, pp. 42-47. (in Japanese).

[12] H. Nakagawa et. Al., 2001, A study on end-milling of hardened steels -Comparison of SKD11 and SKD61-, Journal of the Japan Society for Precision Engineering, Vol. 67, No. 5, pp. 834-838. (in Japanese).

[13] S. Kataoka et. Al., 1995, The use of learning curve theory in estimating production cost, The Bulletin of Toyohashi Junior College, No. 12, pp. 147-161. (in Japanese). 